\title{
ARTICLE \\ The glycaemic index and sports nutrition
}

\section{Potchefstroom Institute of Nutrition, School of Physiology, Nutrition and Consumer Sciences, North-West University, Potchefstroom Hattie H Wright, MSc (Dietetics), PhD (Nutrition), RD (SA)}

Carbohydrate $(\mathrm{CHO})$ is the main fuel for exercising muscles, therefore the amount, timing and type of $\mathrm{CHO}$ food ingested is an important part of an athlete's daily dietary intake. The amount and timing of CHO ingestion has been investigated extensively. It has been suggested that the glycaemic index (GI) of CHO foods influences $\mathrm{CHO}$ availability during exercise and the rate of glycogen synthesis post-exercise. Although low-GI (LGI) CHO foods are mostly recommended for the pre-exercise meal, ingesting high-GI (HGI) CHO foods pre-exercise mostly does not result in hypoglycaemia in healthy individuals during exercise. HGI and LGI CHO foods yield similar results in terms of exercise performance and perceived rate of exertion. HGI and moderate GI (MGI) CHO foods are recommended during exercise. However, fructose in high concentrations is not recommended owing to increased risk of gastrointestinal distress. LGI CHO foods are not recommended during a short recovery period ( $<6$ hours) because of their slow rate of absorption and indigestible $\mathrm{CHO}$, which seems to be a poor substrate for glycogen synthesis.

Carbohydrate (CHO) is the main fuel for exercising muscles, and depletion of glycogen stores has been associated with the onset of fatigue. ${ }^{1,2}$ To maintain and/or resynthesise optimal glycogen stores between training sessions and/or competition the amount, timing and type of $\mathrm{CHO}$ food ingested plays an important role. Ingesting $\mathrm{CHO}$ before exercise is recommended to 'fine tune' glycogen stores, ${ }^{3}$ during endurance-type exercise to provide fuel, ${ }^{4}$ and postexercise to resynthesise glycogen stores. ${ }^{5}$

Extensive investigation has been done into the amount and timing of $\mathrm{CHO}$ ingestion for increased performance and optimal glycogen storage. ${ }^{6,7}$ However, less is known about the type of $\mathrm{CHO}$ needed for optimal performance. Earlier research studies took a very simplistic approach to $\mathrm{CHO}$ nutrition by dividing foods into 'simple' and 'complex' CHOs based on their chemical composition. ${ }^{8-10}$ The ingestion of simple $\mathrm{CHO}$ foods was believed to elicit a large, rapid and short-lived rise in blood glucose, while complex CHO foods were thought to give rise to a flatter and more sustained blood glucose curve. However, this model has recently been challenged with the development of the glycaemic index (GI). Consequently the GI of $\mathrm{CHO}$ foods has been used when selecting foods and CHO-containing fluids to optimise $\mathrm{CHO}$ availability during exercise; GI is also thought to influence the rate of glycogen resynthesis post-exercise, thereby potentially enhancing exercise performance. In general, low-GI (LGI) CHO foods (typically with a GI < 40\%) have been recommended before endurance events to promote $\mathrm{CHO}$ availability during exercise, ${ }^{11} \mathrm{CHO}$ foods with a moderate GI (MGI 63\%, $40-70 \%$ ) to high GI (HGI > 70\%) have been recommended during exercise for readily available $\mathrm{CHO}$ to maintain euglycaemia, and HGI CHO foods have been recommended post-exercise to enhance glycogen storage. ${ }^{12}$ However, some of these recommendations are debatable and require further investigation. The aims of this article were to re-evaluate these general guidelines using recent scientific evidence and to draw conclusions regarding the use of the GI as a tool when choosing $\mathrm{CHO}$ foods in sports nutrition.

\section{$\mathrm{GI}$ and exercise performance}

\section{Pre-exercise}

$\mathrm{CHO}$ ingestion before endurance exercise at submaximal intensity ( 70\% $\mathrm{VO}_{2 \max }$ ) is associated with prolonged cycling time to exhaustion, ${ }^{13}$ enhanced work output, ${ }^{14}$ and time trial performance. ${ }^{15,16}$ It is suggested that pre-exercise $\mathrm{CHO}$ ingestion is important to maintain euglycaemia (4.2 - $5.3 \mathrm{mmol} / \mathrm{l})$ via hepatic glucose output during the latter stages of an endurance event. ${ }^{17}$ However, the ingestion of $\mathrm{CHO}$ in the hour before exercise can result in increased blood glucose and blood insulin levels which presents a potential disadvantage.

Hyperglycaemia and hyperinsulinaemia are often followed by a rapid decline in blood glucose 15 - 30 minutes after the onset of exercise, also referred to as rebound hypoglycaemia $(2.5-2.8 \mathrm{mmol} / \mathrm{l}),{ }^{18,19}$ which can contribute to impaired performance..$^{20,21}$ A small percentage of athletes are especially sensitive to $\mathrm{CHO}$ ingestion during the hour before exercise. Exaggerated $\mathrm{CHO}$ oxidation, decreased blood glucose levels, 
rapid onset of fatigue and symptoms of hypoglycaemia are experienced by these athletes at the onset of exercise. $^{3}$ The precise mechanism for this extreme reaction is not known. ${ }^{22}$ Ingesting a substantial amount of LGI CHO (> $70 \mathrm{~g}$ ) may prevent this. ${ }^{3}$ For more detailed reviews on hypoglycaemia and its treatment see publications by Rutherford ${ }^{19}$ and Brun and coworkers. ${ }^{23}$

Another potential disadvantage of elevated insulin levels before exercise is that this may suppress fat metabolism (free fatty acid (FFA) oxidation) and increase $\mathrm{CHO}$ oxidation, which could contribute to premature depletion of glycogen stores and fatigue..$^{11,24}$ Providing LGI CHO foods before exercise has been proposed to attenuate these metabolic disturbances because of their minimal glycaemic and insulinaemic response. ${ }^{25}$ LGI CHO food consumption pre-exercise has also been hypothesised to result in sustained CHO supply during exercise and increased exercise performance. ${ }^{26}$

Guezennec and co-workers ${ }^{27,28}$ investigated the metabolic response during exercise to isocaloric $\mathrm{CHO}$ foods with different starch structures and starch contents (therefore various GIs) in two separate studies. In both studies subjects ingested the treatments 1 hour pre-exercise (cycling for 2 hours at $60 \% \mathrm{VO}_{2 \max }$ ). In the first study ${ }^{27}$ subjects ingested either glucose (HGI), corn starch (MGI), or fructose (LGI). ${ }^{29}$ Even though blood glucose levels were significantly higher $(p<0.05)$ after HGI and MGI foods 30 minutes postprandially and dropped to values significantly lower (still $>4.0 \mathrm{mmol} / \mathrm{l}$ ) than after the LGI food at 30 minutes of exercise, no differences between treatments were found at the end of exercise ( $t=180$ minutes). The insulin response was higher $(p<0.05)$ when HGI and MGI foods were taken versus LGI food postprandially as well as during the first 120 minutes of the exercise bout, but no differences were seen at the end of exercise. Additionally, there were no differences in serum FFA levels postprandially or during exercise, and there was a similar increase in respiratory exchange ratio (RER) during exercise between all treatments, although $\mathrm{CHO}$ oxidation, as measured by atom per cent excess of ${ }^{13} \mathrm{CO}_{2}$, was lower $(p<0.05)$ after the LGI food versus the HGI and MGI foods at 180 minutes of exercise. In the second study, ${ }^{28}$ cooked spaghetti (LGI), cooked rice (LGI), glucose (HGI), cooked potato (HGI), and bread (HGI) were compared. ${ }^{29}$ Higher $(p<0.05)$ blood glucose levels were found postprandially after HGI versus LGI foods, as well as a drop in blood glucose levels, which were significantly lower after HGI versus LGI foods $(\sim 3.6 \pm 0.2 \mathrm{mmol} / \mathrm{l}$ versus $\sim 4.5 \pm 0.3 \mathrm{mmol} / \mathrm{l})$ at 30 minutes of exercise and at the end of exercise $(\sim 4.0 \pm$ $1 \mathrm{mmol} / \mathrm{l}$ versus $4.7 \pm 0.3 \mathrm{mmol} / \mathrm{l})$. Similarly, blood insulin levels were higher $(p<0.05)$ postprandially after the HGI versus LGI foods, but at 30 minutes of exercise there were no differences between treatments and from baseline values. RER levels increased progressively postprandially after HGI foods but remained unchanged after LGI foods, and were higher $(p<0.05)$ after 30 minutes of exercise in the HGI versus LGI treatment groups. With these two studies ${ }^{27,28}$ the authors supported the concept of sustained $\mathrm{CHO}$ supply from the ingestion of LGI CHO foods pre-exercise due to delayed CHO oxidation. However, it should be noted that exercise performance was not measured. Similar results were shown by Thomas and co-workers, ${ }^{30}$ who found that the GI correlated inversely $(p<0.01)$ with blood glucose levels after more than 90 minutes of exercise (cycling to exhaustion at $65-70 \% \mathrm{VO}_{2 \max }$ ), and with FFA levels $(p<0.05)$ during the last hour of exercise. However there was no difference between treatments in terms of exercise time and no correlation between time to exhaustion and GI. Criticism of this study is that the treatments were not iso-energetic or similar in macronutrient composition, and that the lentil treatment (LGI) provided 208\% more energy and $36 \%$ more protein than the glucose treatment (HGI). In an earlier study ${ }^{31}$ with a similar protocol, Thomas and co-workers also found a higher rate of $\mathrm{CHO}$ oxidation with the ingestion of HGI foods pre-exercise, as well as prolonged endurance time by 20 minutes after the ingestion of LGI foods versus HGI foods. Demarco and co-workers $\mathrm{s}^{32}$ also found an increase in time to exhaustion in a LGI versus HGI pre-exercise meal and speculated that the differences in results were probably due to variations in fibre content of the meals (LGI $57 \mathrm{~g}$ versus HGI $5 \mathrm{~g}$ ). However measurement of performance in both studies was done using a time-to-exhaustion exercise protocol with a fixed submaximal rate, which has a high coefficient of variation $(\sim 25 \%)$ and increases the possibility of errors. ${ }^{33}$

To investigate the influence of GI on glucose homeostasis before and during exercise, Koivisto and Co-workers ${ }^{34}$ compared isocaloric (75 g) fructose (LGI) and glucose (HGI) treatments ingested 45 minutes preexercise (cycling at $70 \% \mathrm{VO}_{2 \max }$, increased by $10 \%$ $\mathrm{VO}_{2 \text { max }}$ after 30 minutes, then cycle to exhaustion). They found similar postprandial increases in blood glucose levels for both treatments, but a drop in blood glucose at 30 minutes of exercise to $2.5 \pm 0.2 \mathrm{mmol} / \mathrm{l}$ in the HGI treatment group which was lower $(p<0.05)$ than in the LGI treatment group. However, they did not report whether subjects experienced any hypoglycaemic symptoms. At the end of exercise there were no differences in blood glucose levels between treatment groups. Blood insulin levels increased twofold postprandially $(p<0.05)$ in the HGI compared with the LGI treatment group, but no differences were found at the end of exercise. Additionally, there were no differences in FFA oxidation, growth hormone and cortisol response, or time to exhaustion between treatments. Febbraio and Stewart ${ }^{35}$ compared an isocaloric LGI meal (lentils) with an HGI meal (mashed potato) ingested 45 minutes pre-exercise (cycling at $70 \% \mathrm{VO}_{2 \max }$ for 120 minutes followed by 1 minute of rest and a work-cycle test for 15 minutes), in terms of 
glycogen utilisation, exercise metabolism and performance. They also found higher $(p<0.01)$ postprandial (15 minutes) blood glucose levels in the HGI versus LGI treatment group, but no difference between treatments at all other time points. Blood glucose levels dropped to a low of $\pm 4.3 \mathrm{mmol} / \mathrm{l}$ in the HGI treatment group at 20 minutes of exercise. Insulin levels were also higher $(p<0.05)$ postprandially in the HGI versus LGI treatment group, but no difference was found between groups from 20 minutes of exercise onwards. There were no differences in glycogen levels post-exercise, or in total work performed. Kirwan and co-workers ${ }^{36}$ also found no difference in time-to-fatigue or glycogen utilisation when a MGI (GI 61) CHO food was ingested 45 minutes pre-exercise compared with a placebo, even with similar glycaemic and insulinaemic responses as in the study by Febbraio and Stewart ${ }^{35}$ and with increased $(p<0.05) \mathrm{CHO}$ oxidation in the MGI versus placebo treatment group. Two studies ${ }^{37,38}$ mimicking practice in their exercise protocols also found no difference between HGI and LGI pre-exercise meals in terms of time to fatigue. However the usual food consumed by subjects in the study by Stannard and $\mathrm{CO}$-workers ${ }^{37}$ was not controlled, therefore a treatment effect could not be isolated. Nevertheless, it was concluded that if an athlete is not sensitive to hypoglycaemia there is little evidence to avoid HGI foods pre-exercise. It should be noted that the potential effect(s) of HGI foods on the mental function of competitive athletes (especially in sports that requires acute reflex responses) requires further investigation.

Garcin and co-workers ${ }^{39}$ investigated the relationship between the GI of the pre-exercise meal and rating of perceived exertion (RPE) or hunger feelings. An isocaloric HGI (GI 100) or LGI (GI 50) food was ingested from 1 hour after a standardised breakfast at 30-minute intervals for a period of 3 hours until 10 minutes before exercise (cycling for 1 hour at $80 \% \mathrm{VO}_{2 \max }$ ). Blood glucose levels were similar in all treatments, although there was a slight drop in the HGI group at 30 minutes of exercise to $4.6 \pm 0.6 \mathrm{mmol} / \mathrm{l}$, but it rose again at 60 minutes of exercise. They found no difference between treatments in RPE or hunger feelings, although water (placebo group) led to increased feelings of hunger $(p<0.05)$ at the end of exercise compared with baseline. Owing to the duration of the exercise protocol it is possible that the RPE could have increased in the HGI group if exercise was prolonged, since maintaining blood glucose is important for local RPE during the latter stages of cycling at $70 \% \mathrm{VO}_{2 \max } \cdot{ }^{40}$

Horowitz and Coyle ${ }^{41}$ compared the effect of $0.7 \mathrm{~g} \mathrm{CHO}$ (sucrose/potato/rice)/kg body weight with or without $0.18 \mathrm{~g}$ fat $/ \mathrm{kg}$ body weight and a placebo, eaten 30 minutes pre-exercise (1 hour incremental cycle test) on the metabolic response before and during exercise, as well as RPE. They found that adding fat to rice and potato significantly blunted the glycaemic and insulinaemic response, but added fat did not influence sucrose's glycaemic and insulinaemic response. Additionally, no differences were found between treatments in terms of RPE. A food containing fat can therefore elicit a high glycaemic response if the CHO portion consists predominantly of syrup solids. Furthermore, RPE after 1 hour of exercise was found to be independent of GI and whether a meal was ingested or not. No differences in exercise performance and metabolic response were found by Mitchell and coworkers ${ }^{42}$ after a $10 \mathrm{~km}$ self-paced performance run when various $\mathrm{CHO}$ solutions with various GIs, ingested 60 minutes pre-exercise, were compared with a water placebo. This raises the question of importance in terms of pre-exercise $\mathrm{CHO}$ ingestion and GI during shorter ( $<1$ hour) events. It should be noted, though, that the sports drinks used in this study showed added benefit in terms of hydration. Having said that, Carter and co-workers ${ }^{43}$ demonstrated improved performance time $(59.57 \pm 1.50$ minutes versus $61.37 \pm 1.56$ minutes, $p=0.011)$ and power output $(259 \pm 16 \mathrm{~W}$ versus $252 \pm$ $16 \mathrm{~W}, p=0.003$ ) after rinsing the mouth with a $6.4 \%$ maltodextrin solution for every $12.5 \%$ of a performance trial completed compared with water (fluids were spat out after a 5-second rinse). There was no difference in $\mathrm{RPE}$ between the 2 trials. These results demonstrate that exercise performance is also influenced by a central drive (brain) or motivation, which might have been through the brain in response to sensory perception by mouth receptors.

Burke and co-workers ${ }^{44}$ showed that if $\mathrm{CHO}(\sim 1 \mathrm{~g}$ glucose/minute) is ingested during exercise (incremental cycle test to exhaustion) the GI of the preexercise meal (HGI versus LGI) has no effect on performance, and glycaemic differences at the onset of exercise are short-lived. In that study most subjects preferred to ingest the LGI CHO meal as a pre-exercise meal. It seems, therefore, that if the total amount of $\mathrm{CHO}$ ingested pre-exercise is sufficient (1.1 - $2 \mathrm{~g}$ $\mathrm{CHO} / \mathrm{kg} 1-2$ hours pre-exercise $)^{16}$ and if $\mathrm{CHO}$ is ingested during exercise, the type of $\mathrm{CHO}$ in the preexercise meal can be determined according to the individual's preference and previous experience.

\section{During exercise}

$\mathrm{CHO}$ ingestion during prolonged submaximal intensity and intermittent intensity exercise has been associated with increased performance..$^{13,45,46}$ Additionally, it might be beneficial for high-intensity exercise ( \pm 1 hour duration) in terms of performance. ${ }^{47,48}$ Mechanisms for improved exercise performance as a result of $\mathrm{CHO}$ ingestion during exercise of \pm 1 hour are unclear, since only 5 - $15 \mathrm{~g}$ of ingested glucose could have been oxidised at the end of exercise, ${ }^{47}$ and it is unlikely that this small amount could contribute to the relatively large effect on performance. It has been suggested that benefits to 'central performance' involving the brain and nervous system are involved as previously discussed. ${ }^{43}$ Although CHO ingestion during exercise 
compared with a placebo can increase performance, ingesting $\mathrm{CHO}$ before and during exercise can result in an even greater endurance time and work output. ${ }^{13}$

Apart from performance advantages, $\mathrm{CHO}$ ingestion during exercise helps to maintain euglycaemia (> 2.5 $\mathrm{mmol} / \mathrm{l}),{ }^{49}$ to supplement endogenous stores during the latter stages of exercise, ${ }^{50}$ and to decrease cytokine and cortisol concentration during exercise, all of which have been associated with diminished physiological stress. ${ }^{51}$

As with pre-exercise $\mathrm{CHO}$ intake, the amount, timing and type of $\mathrm{CHO}$ ingested during exercise influences exercise performance. For maximal exogenous CHO oxidation it is recommended to ingest $1.0-1.1$ $\mathrm{g} /$ minute (60 - $70 \mathrm{~g} \mathrm{CHO} / \mathrm{hour}$ ), ${ }^{52}$ to start $\mathrm{CHO}$ ingestion early ( $<60$ minutes) during the event, and to ingest $\mathrm{CHO}$ at 15-minute intervals. ${ }^{4,53}$ However, the suggested frequency of $\mathrm{CHO}$ ingestion might not always be practical because of time lost when ingesting food during a competition, possible risk of gastrointestinal distress, and frequency of formal and informal pauses during team sports. ${ }^{4}$

Consumption of fructose (LGI) while exercising is often promoted because of the low insulinaemic response..$^{54}$ Low insulinaemic response would therefore increase FFA oxidation, thereby sparing $\mathrm{CHO}$ oxidation (decreased glycogen depletion) and contributing to prolonged time to exhaustion. ${ }^{27}$ However this argument is not well founded since insulin secretion is suppressed during exercise. ${ }^{55}$ Additionally, fructose in high concentrations is associated with gastrointestinal distress, ${ }^{56}$ fructose oxidation is slower than that of glucose (HGI) probably owing to a lower rate of absorption and because it first needs to be converted to glucose in the liver before it can be metabolised. ${ }^{52}$ Furthermore, fructose has been shown to decrease exercise capacity compared with glucose. ${ }^{56}$ Fructose does, however, increase palatability of a drink ${ }^{52}$ and when added to a glucose drink $(1.2 \mathrm{~g} /$ minute maltodextrin $+0.6 \mathrm{~g} /$ minute fructose) can increase exogenous $\mathrm{CHO}$ oxidation rates by $40 \%$ compared with an iso-energetic glucose-only drink (1.50 \pm 0.07 versus $1.06 \pm 0.08 \mathrm{~g} /$ minute). ${ }^{57}$ Recently, Jentjens and Jeukendrup ${ }^{58}$ increased exogenous $\mathrm{CHO}$ oxidation rates to approximately $1.75 \mathrm{~g} /$ minute when giving a higher rate $(2.4 \mathrm{~g} /$ minute) of a glucose-fructose mixture (1.2 $\mathrm{g} /$ minute glucose $+1.2 \mathrm{~g} /$ minute fructose) to trained male cyclists during an exercise trial (150 minutes at $50 \%$ of maximal power output). The increased exogenous $\mathrm{CHO}$ oxidation rates of combined $\mathrm{CHO}$ (glucose, fructose and sucrose) drinks compared with glucose-only drink may be due to less competition for absorption as different intestinal transport mechanisms are used.

Generally, rapidly oxidisable CHOs (HGI and MGI) are recommended during exercise and include glucose (HGI), maltose (HGI), sucrose (MGI), maltodextrins
(HGI) and amylopectin (MGI).29,52 These CHOs are used in studies because of their rapid rate of digestion, which results in increased blood glucose levels during exercise and therefore maintenance of euglycaemia. ${ }^{59}$ LGI CHOs have a slower digestion and absorption rate $^{59,60}$ which might result in hypoglycaemia. Additionally, this slower rate of digestion might increase the risk of gastrointestinal distress when ingested during exercise ${ }^{61}$ Furthermore, as a result of colonic fermentation less available CHOs are absorbed and therefore less energy is produced compared with an equal amount of HGI food. This may result in a net loss of energy to exercising muscle. ${ }^{62}$

\section{GI and recovery}

From a nutritional perspective, the recovery phase post-exercise is characterised by glycogen resynthesis, and whole-body protein synthesis. ${ }^{63,64}$ Once again, the amount, type and timing of $\mathrm{CHO}$ intake plays an important role in the rate of glycogen synthesis, and contributes to the rate of whole-body protein synthesis. ${ }^{6,64}$ During short-term recovery periods $(<8$ hours) the type and timing of $\mathrm{CHO}$ consumed is more important than during longer recovery periods ( $>8$ hours), although the amount of $\mathrm{CHO}$ ingested remains important during both recovery periods. ${ }^{65,66}$ Currently, it is recommended to ingest $1.0-1.85 \mathrm{~g} / \mathrm{kg} /$ hour immediately post-exercise and at 15 - 60-minute intervals thereafter, for up to 5 hours post-exercise ${ }^{6}$ during a short-term recovery period. During a longer recovery period total daily $\mathrm{CHO}$ intake should be sufficient $(\sim 7-10 \mathrm{~g} / \mathrm{kg} /$ day $) .{ }^{67}$

From 60 minutes onwards post-exercise, the rate of glycogen synthesis is inter alia dependent on muscle contraction and insulin owing to their stimulatory effect on the activity of glycogen synthase ${ }^{68,69}$ the ratelimiting enzyme in glycogen synthesis. ${ }^{70}$ Since various CHOs have various glycaemic and insulinaemic responses, ${ }^{71} \mathrm{CHO}$ oxidation as well as digestion and absorption rates ${ }^{53}$ it is clear that the type of $\mathrm{CHO}$ ingested post-exercise will influence the rate of glycogen synthesis.

HGI CHO foods are currently recommended during the recovery period owing to their high insulinaemic and glycaemic response ${ }^{26}$ Earlier studies investigating the type of $\mathrm{CHO}$ and its effect on glycogen synthesis are difficult to interpret since $\mathrm{CHO}$ was still classified as 'simple' and 'complex', for example fructose (LGI) was classified as a 'simple' CHO. ${ }^{9}$ Additionally, glucose and insulin responses were not always measured and the foods used were not always well described. However Blom and co-workers ${ }^{72}$ found an increased rate of glycogen synthesis $(p<0.05)$ after the ingestion of glucose and sucrose (0.7 g CHO/kg 2 - 6 hours post exercise) compared with fructose post-exercise (cycle test to exhaustion at $75 \% \mathrm{VO}_{2 \max }$ ). In retrospect we now know that HGI and MGI CHO foods result in a higher rate of glycogen synthesis than LGI CHO foods 
during a 6-hour recovery period. Kiens and coworkers ${ }^{73}$ also found greater storage of glycogen at 6 hours post-exercise when the subjects consumed HGI versus LGI foods. However, no difference between HGI and LGI foods was found at 20, 32 and 44 hours postexercise. Although it is difficult to interpret the results of this study as the terms simple or HGI and complex or LGI were used interchangeably, it would appear that if the recovery period is longer the total amount of $\mathrm{CHO}$ ingested is more important in terms of glycogen synthesis than the type of $\mathrm{CHO}$ ingested. This hypothesis was supported by the findings of Burke and Co-workers in two follow-up studies. ${ }^{74,75}$ The first study measured the amount of glycogen stored at 24 hours post-exercise. ${ }^{74}$ Subjects were given either a LGI (total GI 71) or HGI diet (total GI 108) divided into 4 meals during the recovery period ( $10 \mathrm{~g} \mathrm{CHO} / \mathrm{kg} /$ day) postexercise (2-hour cycle at 75\% $\mathrm{VO}_{2 \max }$ followed by 4 x 30 second 'all-out' sprints with 2 -minute rest periods). A higher level $(p<0.02)$ of glycogen storage was found in the HGI versus the LGI diet group (106.1 \pm 11.7 versus $71.5 \pm 6.5 \mathrm{mmol} / \mathrm{kg}$ wet weight). However these findings were difficult to explain since the magnitude of increase in glycogen storage with the HGI diet group was greater than the 24-hour blood glucose and insulin response. In the follow-up study, Burke and coworkers ${ }^{75}$ simulated the flattened glucose and insulin response of a LGI diet by giving 16 small HGI snacks (10 g CHO/kg/day) over a period of 24 hours postexercise and compared this with the effect of 4 HGI meals (10 g CHO/kg/day) over the same period in terms of glycogen storage. Despite differences in glucose and insulin responses, no differences were found in glycogen storage between the two trials at 24 hours post-exercise. Therefore, manipulating glucose and insulin levels during a longer recovery period is not critical for optimal glycogen storage, as long as the total amount of CHO ingested is sufficient $(\sim 7-10 \mathrm{~g}$ $\mathrm{CHO} / \mathrm{kg} /$ day). ${ }^{2,67}$

A possible explanation for increased glycogen storage after HGI versus LGI CHO foods during a shorter recovery period post-exercise, is that a considerable amount of $\mathrm{CHO}$ in LGI food is not absorbed ${ }^{76}$ and the indigestible $\mathrm{CHO}$ forms of LGI foods provide a poor substrate for glycogen synthesis. ${ }^{77}$ Furthermore, as mentioned earlier fructose (LGI) yields a slower rate of glycogen synthesis than glucose, possibly because of its slower rate of absorption and the fact that fructose first needs to be converted to glucose in the liver before it can be metabolised in the skeletal muscle..$^{78,79}$ Interestingly though, similar rates of glycogen synthesis have been found when either glucose (HGI) or sucrose (MGI) was ingested. ${ }^{72,80}$ Since sucrose contains equimolar amounts of glucose and fructose, only half the amount of glucose is directly available for glycogen synthesis. It is suggested that fructose may inhibit post-exercise hepatic glucose uptake, therefore more glucose may escape the liver and be available for muscle glycogen synthesis. ${ }^{72}$ Piehl Aulin and co- workers ${ }^{81}$ found that a post-exercise $\mathrm{CHO}$ drink containing glucose polymers (HGI) resulted in a higher rate $(p<0.05)$ of glycogen synthesis 4 hours postexercise than an iso-energetic glucose-containing (HGI) drink $(50.2 \pm 13.7$ versus $29.9 \pm 12.5 \mathrm{mmol} / \mathrm{kg}$ dry weight/hour). It was suggested that the lower osmolality of the glucose polymer drink versus the glucose drink (84 versus $350 \mathrm{mOsm} / \mathrm{l}$ ) led to greater gastric emptying rates and a faster delivery of substrate to muscle. Although there was no difference in insulin and glucose response, there could have been a greater non-insulin-dependent uptake of glucose in the muscle during the early (30 - 60-minute) post-exercise period. This hypothesis merits further investigation.

The effect of the GI on whole-body protein synthesis has not been investigated extensively. Levenhagen and co-workers ${ }^{64}$ fed their subjects the same supplement immediately post-exercise (cycle at 70\% $\mathrm{VO}_{2 \max }$ for 1 hour) or 3 hours post-exercise (8 g sucrose $+10 \mathrm{~g}$ protein $+3 \mathrm{~g}$ fat/serving). Immediate ingestion of the supplement post-exercise led to an enhanced accretion of whole-body and skeletal muscle protein $(p<0.05)$. It was concluded that combining a highinsulinogenic and HGI CHO with protein immediately post-exercise is a potent stimulator for protein synthesis, probably owing to increased insulin secretion (favourable hormonal mileu) and amino acid availability. In a recent review by Suzuki ${ }^{22}$ it was also concluded that HGI CHO is more effective than LGI $\mathrm{CHO}$ for skeletal muscle formation.

\section{Conclusion and recommendations}

The main interest in the application of the GI in sports nutrition is related to the potential to enhance sports performance. It is therefore important that when investigating the effect of GI on metabolic response and/or exercise performance the exercise protocols used are relevant and reliable. The preferred exercise protocols to use are those mimicking practice. Many studies use a 'time to exhaustion at a fixed rate' exercise protocol which has a high coefficient of variation, thereby increasing the risk of error in results. When interpreting results it is therefore important to keep the exercise protocol in mind.

The importance of the pre-exercise meal is largely determined by the degree of recovery from the previous exercise session ${ }^{66}$ and the duration of the exercise event. When choosing a pre-exercise meal, gastric emptying, digestion and absorption rate should be considered to limit possible gastrointestinal distress and excessive fullness. ${ }^{52,66}$ Ingesting HGI CHO foods pre-exercise usually results in a drop in blood glucose levels at 15 - 30 minutes of exercise which stabilises again at approximately 60 minutes of exercise. However this drop largely does not result in hypoglycaemia $(<2.5 \mathrm{mmol} / \mathrm{l})$ and rarely causes 
hypoglycaemic symptoms. Furthermore, LGI CHO preexercise foods do not increase exercise performance, although these foods cause delayed $\mathrm{CHO}$ oxidation and increased FFA oxidation compared with HGI CHO preexercise foods. Therefore, based on current findings, HGI CHO foods can be ingested pre-exercise without any detrimental effects if preferred by an athlete, and if the athlete is not sensitive to hypoglycaemia.

Ingesting $\mathrm{CHO}$ during exercise increases exercise performance (even in events $\leq 1$ hour in duration), helps to maintain euglycaemia, and decreases the risk of upper respiratory tract infection (URTI). HGI and MGI CHOs are generally recommended during exercise because of the rapid digestion of the $\mathrm{CHO}$ and maintenance of euglycaemia. High concentrations of fructose are not recommended because of the latter's association with gastrointestinal distress. However combining different CHOs (including fructose) could increase palatability as well as water and $\mathrm{CHO}$ absorption.

HGI and MGI CHO foods appear to be the best choice post-exercise when the recovery period is short $(<8$ hours) because of the insulinaemic response of these CHOs which stimulate glycogen synthese activity and hence an increase in the rate of glycogen synthesis. LGI CHO food is not recommended during this recovery period, since it has a slower rate of absorption and its indigestible $\mathrm{CHO}$ appears to be a poor substrate for glycogen synthesis. However if the recovery period is longer ( $\geq 22$ hours) the total amount of $\mathrm{CHO}$ ingested is more important than the GI per se. Combining HGI and MGI CHO with protein seems to be more beneficial for whole-body protein synthesis post-exercise, than LGI CHO and protein.

Further research is needed on the effect of the GI on exercise performance using exercise protocols that mimic practice, and on protein synthesis during the recovery phase.

1. Romijn JA, Coyle EF, Sidossis LS, et al. Regulation of endogenous fat in carbohydrate metabolism in relation to exercise intensity and duration. Am J Physiol 1993; 265: E380-E391.

2. Costill DL. Carbohydrates for exercise: dietary demands for optimal performance. Int $J$ Sports Med 1988; 9: 1-18

3. Burke L. Preparation for competition. In: Burke L, Deakin V, eds. Clinical Sports Nutrition. 2nd ed. Sydney: McGraw-Hill Australia, 2000: 341-368.

4. Maughan R. Fluid and carbohydrate intake during exercise. In: Burke L, Deakin V, eds Clinical Sports Nutrition. 2nd ed. Sydney: McGraw-Hill Australia, 2000: 369-395.

5. Burke L. Nutrition for recovery after competition and training. In: Burke L, Deakin V, eds. Clinical Sports Nutrition. 2nd ed. Sydney: McGraw-Hill Australia, 2000: 396-425.

6. Jentjens RL, Jeukendrup AE. Determinants of post-exercise glycogen synthesis during short-term recovery. Sports Med 2003; 33: 117-144.

7. Jentjens RL, Van Loon LJC, Mann CH, Wagenmakers AJM, Jeukendrup AE. Addition of protein and amino acids to carbohydrates does not enhance post-exercise muscle glycogen synthesis. J Appl Physiol 2001; 91: 839-846.

8. Brewer J, Williams C, Patton A. The influence of high carbohydrate diets on endurance running performance. Eur J Appl Physiol Occup Physiol 1988; 57: 698-706.

9. Costill DL, Sherman WM, Fink WJ, et al. The role of dietary carbohydrates in muscle glycogen resynthesis after strenuous running. Am J Clin Nutr 1981; 34: 1831-1836.

10. Roberts KM, Noble EG, Hayden DB, Taylor AW. Simple and complex carbohydrate-rich diets and muscle glycogen content of marathon runners. Eur J Appl Physiol Occup Physiol 1988; 57: 70-74

11. Hargreaves M, Costill DL, Katz A, Fink WJ. Effect of fructose ingestion on muscle glycogen usage during exercise. Med Sci Sports Exerc 1985; 17: 360-363.

12. Gretenbeck RJ, Gretebeck KA, Tittelbach TJ. Glycemic index of popular sport drinks and energy foods. J Am Diet Assoc 2002; 102: 415- 417.

13. Wright DA, Sherman WM, Dernbach AR. Carbohydrate feedings before, during or in combination improve cycling endurance performance. J Appl Physiol 1991; 71: 10821088
14. Neufer PD, Costill DL, Flynn MG, et al. Improvements in exercise performance: effects of carbohydrate feedings and diet. J Appl Physiol 1987; 62: 983-988.

15. Sherman WM, Brodowicz G, Wright DA, et al. Effects of $4 \mathrm{~h}$ preexercise carbohydrate feedings on cycling performance. Med SCi Sports Exerc 1989; 21: 598-604

16. Sherman WM, Peden MC, Wright DA. Carbohydrate feedings $1 \mathrm{~h}$ before exercise improves cycling performance. Am J Clin Nutr 1991; 54: 866-870.

17. Kirwan JP, O'Gorman D, Evans WJ. A moderate glycaemic meal before endurance exercise can enhance performance. J Appl Physiol 1998; 84: 53-59.

18. Wahren J, Felig P, Ahlborg G, Jorfeldt L. Glucose metabolism during leg exercise in man. J Clin Invest 1971; 50: 2715-2725

19. Rutherford WJ. Hypoglycemia and endurance exercise: dietary considerations. Nutr Health 1990; 6: 173-181.

20. Coggan AR, Coyle EF. Reversal of fatigue during prolonged exercise by carbohydrate infusion or ingestion. J Appl Physiol 1988; 63: 2388-2395.

21. Costill DL, Coyle E, Dalsky G, et al. Effects of elevated plasma FFA and insulin on muscle glycogen usage during exercise. J Appl Physiol 1977; 43: 695-699.

22. Jentjens RL, Jeukendrup AE. Prevalence of hypoglycemia following pre-exercise carbohydrate ingestion is not accompanied by higher insulin sensitivity. Int J Sport Nutr Exerc Metabol 2002 12: 398-414.

23. Brun JF, Dumortier M, Fedou C, Mercier J. Exercise hypoglycemia in nondiabetic subjects. Diabetes Metab 2001: 27(2Pt1): 92 - 106

24. Foster C, Costill DL, Fink WJ. Effects of preexercise feedings on endurance performance. Med Sci Sports 1979; 11(1): 1-5.

25. Decombaz J, Sartori D, Arnaud MJ, et al. Oxidation and metabolic effects of fructose or glucose ingested before exercise. Int J Sports Med 1985; 6: 282-286.

26. Brand Miller J, Foster-Powell K, Colagiuri S. The GI factor. Sydney: Hodder and Stoughton, 1996: 20-37.

27. Guezennec CY, Stabin P, Duforez F, et al. Oxidation of corn starch, glucose and fructose ingested before exercise. Med Sci Sports Exerc 1989; 21(1): 45-50

28. Guezennec CY, Satabin P, Duforez F, et al. The role of type and structure of complex carbohydrates response to physical exercise. Int J Sports Med 1993; 14: 224-231.

29. Brand-Miller J, Foster-Powell K. The Glucose Revolution, GI Plus. Sydney: Hodder \& Stoughton, 2000: 215-233

30. Thomas DE, Brotherhood JR, Brand Miller J. Plasma glucose levels after prolonged strenuous exercise correlate inversely with glycaemic response to food consumed before exercise. Int J Sport Nutr 1994; 4: 361-373.

31. Thomas DE, Brotherhood JR, Brand JC. Carbohydrate feeding before exercise: effect of glycemic index. Int J Sports Med 1991; 12: 180-186.

32. DeMarco HM, Sucher KP, Cisar CJ, Butterfield GE. Pre-exercise carbohydrate meals: application of glycaemic index. Med Sci Sports Exerc 1999; 31(1): 164-170.

33. McClellan TM, Cheung SS, Jacobs I. Variability of time to exhaustion during submaximal exercise. Can J Appl Physiol 1995; 20: 39-51

34. Koivisto VA, Karonen S-L, Nikkilä E. Carbohydrate ingestion before exercise: comparison of glucose, fructose, and sweet placebo. J Appl Physiol 1981; 51: 783-787.

35. Febbraio MA, Stewart KL. CHO feeding before prolonged exercise: effect of glycaemic index on muscle glycogenolysis and exercise performance. J Appl Physiol 1996; 81: 1115-1120.

36. Kirwan JP, O'Gorman DJ, Cyr-Campbell D, et al. Effects of a moderate glycaemic meal on exercise duration and substrate utilization. Med Sci Sports Exerc 2001; 33: 15171523 .

37. Stannard SR, Thompson MW, Brand Miller JC. The effect of glycaemic index on plasma glucose and lactate levels during incremental exercise. Int J Sport Nutr Exerc Metabol 2000; 10: 51-61

38. Wee S-L, Williams C, Gray S, Horabin J. Influence of high and low glycaemic index meals on endurance running capacity. Med Sci Sports Exerc 1999; 31: 393-399.

39. Garcin M, Piton A, Brésillion S, Pérès G. Does perceived exertion depend on glycaemic index of foods ingested throughout three hours before a one-hour high-intensity exercise? Percept Mot Skills 2001; 93: 599-608.

40. Burgess ML, Roberston RJ, Davis JM, Norris JM. RPE, blood glucose, and carbohydrate oxidation during exercise: effects of glucose feedings. Med SCi Sports Exerc 1991; 2: 92-98.

41. Horowitz JF, Coyle EF. Metabolic responses to preexercise meals containing various carbohydrates and fat. Am J Clin Nutr 1993; 58: 235-241.

42. Mitchell JB, Braun WA, Pizza FX, Forrest M. Pre-exercise carbohydrate and fluid ingestion: influence of glycaemic response on $10-\mathrm{km}$ treadmill running performance in the heat. J Sports Med Phys Fitness 2000; 40: 41-50

43. Carter JM, Jeukendrup AE, Jones DA. The effect of carbohydrate mouth rinse on 1-h cycle time trial performance. Med Sci Sports Exerc 2004; 36: 2107-2111.

44. Burke L, Claassen A, Hawley JA, Noakes TD. Carbohydrate intake during prolonged cycling minimizes effect of glycaemic index of preexercise meal. J Appl Physiol 1998; 85: $2220-2226$

45. Coggan AR, Coyle EF. Carbohydrate ingestion during prolonged exercise: effects on metabolism and performance. Exerc Sport SCi Rev 1991; 19: 1-40.

46. Vergauwen L, Brouns F, Hespel P. Carbohydrate supplementation improves stroke performance in tennis. Med Sci Sports Exerc 1998; 30: 1289-1295.

47. Jeukendrup AE, Brouns F, Wagenmakers AJM, et al. Carbohydrate feedings improve 1 h time trial cycling performance. Int J Sports Med 1997; 18: 125-129.

48. Below P, Mora-Rodriguez R, Gonzalez-Alonso J, Coyle EF. Fluid and carbohydrate ingestion independently improve performance during $1 \mathrm{~h}$ of intense cycling. Med Sc Sports Exerc 1995; 27: 200-210.

49. Costill DL, Bennett A, Branam G, Eddy D. Glucose ingestion at rest and during prolonged exercise. J Appl Physiol 1973: 34: 764-769.

50. Coyle EF. Fuels for sport performance. In: Lamb DR, Murray R, eds. Perspectives in Exercise Science and Sports Medicine. Vol. 10. Optimising Sport Performance. Carmel: Benchmark Press, 1997: 95-138.

51. Nieman DC. Influence of carbohydrate on the immune response to intensive, prolonged exercise. Exerc Immunol Rev 1998; 4: 64-76.

52. Jeukendrup $\mathrm{AE}$, Jentiens R. Oxidation of carbohydrate feedings during prolonged exercise: current thoughts, guidelines and directions for future research. Sports Med 2000; 29: 407-425.

53. McConell G, Kloot K, Hargraeves M. Effect of timing of carbohydrate ingestion on endurance exercise performance. Med Sci Sports Exerc 1996; 28: 1300-1304.

54. Samols E, Dormandy TL. Insulin response to fructose and galactose. Lancet 1963; I: $478-479$ 
55. Broun F, Rehrer NJ, Saris WHM, et al. Effect of carbohydrate intake during warm-up on the regulation of blood glucose during exercise. Int J Sports Med 1989; 10: S68-

56. Murray R, Gregory LP, Seifert JG, et al. The effects of glucose, fructose, and sucrose ingestion during exercise. Med Sci Sports Exerc 1989; 21: 275-282

57. Wallis GA, Rowlands DS, Shaw C, et al. Oxidation of combined ingestion of maltodextrins and fructose during exercise. Med Sci Sports Exerc 2005; 37: 426-432

58. Jentjens RL, Jeukendrup AE. High rates of exogenous carbohydrate oxidation from a mixture of glucose and fructose ingested during prolonged cycling exercise. Br J Nutr 2005; 93: 485-492.

59. Walton P, Rhodes EC. Glycaemic index and optimal performance. Sports Med 1997; 23 164-172.

60. Saris WHM, Goodpaster BH, Jeukendrup AE, et al. Exogenous carbohydrate oxidation from different carbohydrate sources during exercise. J Appl Physiol 1993; 75: 21682172.

61. Wursch P. Del Vedovo S, Koell Reutter B. Cell structure and starch nature as key determinants of the digestion rate of starch in legume. Am J Clin Nutr 1986; 43: 25-29.

62. Anderson IM, Levine AS, Levitt MD. Incomplete absorption of the carbohydrate in allpurpose wheat flour. N Engl J Med 1981; 15: 891-892.

63. Piehl $\mathrm{K}$. Time course for refilling glycogen stores in human muscle fibres following exercise-induced glycogen depletion. Acta Physiol Scand 1974; 90: 297-302.

64. Levenhagen DK, Gresham JD, Carlson MG, et al. Postexercise nutrient intake timing in humans is critical to recovery of leg glucose and protein homeostasis. Am J Physiol Endocrinol Metab 2001: 280: E982-E993.

65. Ivy JL, Katz AL, Cutler CL, et al. Muscle glycogen synthesis after exercise: effect of time of carbohydrate ingestion. J Appl Physiol 1988; 64: 1480-1485.

66. Burke L, Gregory RC, Hargraeves M. Glycemic index - a new tool in sports nutrition? Int J Sport Nutr 1998; 8: 401-415

67. Coyle EF. Timing and method of increased carbohydrate intake to cope with heavy training, competition and recovery. J Sports SCi 1991; 9(S): 29-52.

68. Cartee GD, Young DA, Slepper MD, et al. Prolonged increase in insulin-stimulated glucose transport in muscle after exercise. Am J Physiol 1989; 256: E494-E499.

69. Gao J, Gulve EA, Holloszy JO. Contraction-induced increase in muscle insulin sensitivity: requirement for a serum factor. Am J Physiol 1994; 266(2 Pt 1): E186-E192.
70. Danforth WH. Glycogen synthetase activity in skeletal muscle. Interconversion of two forms and control of glycogen synthesis. J Biol Chem 1965; 240: 588-593.

71. Wolever MS, Jenkins DJA, Jenkins AL, Josse RG. The glycaemic index: methodology and clinical implications. Am J Clin Nutr 1991; 54: 846-854

72. Blom PSC, Hostmark AT, Vaage O, et al. Effect of different post-exercise sugar diets on the rate of muscle glycogen synthesis. Med Sci Sports Exerc 1987; 19: 491-496.

73. Kiens B, Raben AB, Valeur AK, Richter EA. Benefit of simple carbohydrates on the (abstract). Med SCi Sports Exerc 1990; 22: Suppl 4; S88.

74. Burke L, Collier G, Hargreaves M. Muscle glycogen storage after prolonged exercise: effect of the glycaemic index of carbohydrate feedings. J Appl Physiol 1993; 75: 10191023

75. Burke LM, Collier GR, Davis PG, et al. Muscle glycogen storage following prolonged exercise: effect of the frequency of carbohydrate feedings. Am J Clin Nutr 1996; 64: 115-119.

76. Wolever TMS, Cohen Z, Thompson LU, et al. Ileal loss of available carbohydrate in man: comparison of a breath hydrogen method with direct measurement using a human ileostomy model. Am J Gastroenterol 1986; 81: 115-122.

77. Joszi AC, Trappe TA, Starling RD, et al. The influence of starch structure on glycogen resynthesis and subsequent cycling performance. Int J Sports Med 1996; 17: 373-378.

78. Henry RR, Crapo PA, Thorburn AW. Current issues in fructose metabolism. Annu Rev Nutr 1991; 11: 21-39.

79. Conlee RK, Lawler RM, Ross PE. Effects of glucose or fructose feeding on glycogen repletion in muscle and liver after exercise or fasting. Ann Nutr Metab 1987; 31: 126132.

80. Casey A, Mann R, Banister $\mathrm{K}$, et al. Effect of carbohydrate ingestion on glycogen resynthesis in human liver and skeletal muscle, measured by 13C MRS. Am J Physiol 2000; 278: E65-E75.

81. Piehl Aulin K, Söderlund K, Hultman E. Muscle glycogen resynthesis rate in human after supplementation of drinks containing carbohydrates with low and high molecula masses. Eur J Appl Physiol 2000; 81: 346-351.

82. Suzuki M. Glycemic carbohydrates consumed with amino acids or protein right after exercise enhances muscle formation. Nutr Rev 2003; 61: S88-S94. 